and evidently in pain. The parents were both healthy, and had three other children, all of whom were strong and well. On examining the eye, the glioma was at once recognised by the bright yellow $r \in f l e x$, which was seen without dilating the pupil with atropine. The growth occupied a considerable portion of the vitreous space, but had not advanced sufficiently to press forward the lens and iris; the bumours were perfectly clear. I advised the mother to have the eye excised; and, after a fortnight's consideration, she gave her consent.

The eye was removed in the usual manner; and, nn making a section of the globe, a soft glioma, about the gize of a large borse-bean, was seen growing from the retina between the outer side of the optic nerve and the ciliary processes, aud extending into the vitreous. A part of the growth had undergone fatty and chalky degeneration; it had become semi-fluid, and scattered amongst the soft portion were some chalky fragments. The tumour had evidently been of longer duration than eight weeks (the age of the child), and had probably existed for some time in utero.

The child recovered rapidly from the operation, and was evidently much relieved by the removal of the eye. Harles-street, W.

\section{REMARKS ON A \\ CASE ILLUSTRATING THE OCCASIONAL PROTRACTED COURSE OF MALIGNANT (SCIRRHOUS) DISEASE OF THE STOMACH.}

BY I. BURNEY YEO, M.D., M.R.C.P.,

BENIOS ASSISTANT-PHYSTCIAN TO KING'S COLLEGE HOSPITAL; ASSISTANTPHYSICIAN TO THE BROMPTON HOSPITAL.

Tre following case, besides being interesting in many of its details, affords proof of a fact which is perhaps not very widely known-viz, that scirrhous disease of the stomach occasionally runs a very protracted course, and extends over a period of ten, fifteen, or even twenty years. The patient in question died in 1874 ; he first suffered severe gastric pain in 1857.

For the first part of the history of this case $I$ am indebted to the kindness of Dr. Wilson Fox, who was consulted by the patient in August, 1868, he being at that time fifty-five years of age.

'The following are Dr. Wilson Fox's notes:- "He first felt severe gastric pains in 1857 , relieved by sulphuric acid, but it continued at intervals until 1861, when it increased in severity and became attended by acid romiting. The vomited matters were never black or bloody. Fæces at this time black but not tarry; appetite lost. In the spring of 1868 , after suffering from pain, great weakness, and loss of appetite, he suddenly became faint. The stomach became distended and painful, and the pain radiated across the chest. At this time he passed tarry stools repeatedly on several occasions, and they were seen, certainly on one occasion, by Dr. Grimsdale, of Liverpool. He suffered from frequent vomiting after food. His attacks of vomiting were associated with anorexia; these attacks would last for about a week, when the appetite would return and become ravenous. The vomited matters were acid, but not frothy, nor had they even the appearance of coffee-grounds. There was no increase of pain before passing the tarry evacuations. He stated that the pain in 1861 used to be relieved by eating, and would return three or four hours after food."

Dr. Fox further noted that the patient presented at this time an appearance of intense pallor; that there was no tenderness or tumour in the region of the stomach; that there were no piles, though $h \in$ had suffered from them some sears ago. The diagnosis was " carcinoma ventriculi"

The patient first consulted me in November, 1870, and complained of symptoms of dyspepsia. He told me of the unfavourable opinion Dr. Wilson Fox had formed of his cage in 1968, but added that he had subsequently consulted a very eminent physician in London, who had given him a more favourable opinion, which he was himself disposed to accept-viz, that he was suffering from functional dyspepsia.
He was a gentleman of very great energy both of body and mind; he was in the habit of taking very active exercise, and of consuming a large amount of food, and his chief trouble was severe pain, with flatulence and acid eructations on going to bed at night-i.e., three or four hours after his dinner.

There was no tenderness or tumour in the region of the stomach or over any part of the abdominal cavity, but he was emaciated, and had a pinched and unhealthy aspect.

A day or two after first consulting me he was seized with very severe pain, and I was sent for to see him, but being out of town he passed under the care of a homcopatbic practitioner at Highgate, where he lived, and I saw no more of him until the autumn of 1873. In Ootober of that rear he called on me to tell me he was quite well, that the fons et origo mali (I use his own words) had been discovered. That the fact was, he had all along been suffering from gall-stones, and that two seasons at Carlsbad and a winter in Algeria had set him right. He did not mention then, what I discovered subsequently, that he bad been taught to use morphia bypodermically for the relief of the stomach pain, and to this fact must be attributed much of the obscurity which appeared hereafter to hang over his case.

He passed through the winter of $1873-74$ comfortably, in the firm belief that all his previous sufferings had been due to gall-stones, and that, should they ever return, he had a certain resource in the Carlsbad waters.

In April, 187., I was asked to see his wife at Norwood, and, observing that he was not well, I was told, incidentally, that he was suffering from another attack of gall-stone, but that he knew quite well how to manage himself : he was drinking a large quantity of the Carlsbad water; and when the pain was very severe, he obtained certain relief by the injection of morphia hypodermically. I was simply referred to by his wife to know if it was right for him to have recourse so constantly to this mode of relieving his symptoms: a question which was then, and on many subsequent orcasions, pertinently answered by the patient, who demanded why he should be allowed to suffer pain when an easy and safe means of relieving it was in his own hands.

I did not see him again until the end of the following month (May, 1874), when I was summoned to see him as he was passing through town on his way to the north. I found him very ill, suffering intense pain in the stomach, vomiting everything he took, and passing black motions, consisting of fluid and solid matters, the latter composed partly of broken-down scybala and partly of black gritty powder. The pulse was weak, and the tongue red and thinly covered with a brownish fur. The superficial arteries were markedly atheromatous. I asked to see the matters vomited, and found them to consist wholly of the farinaceous foods which had been given him; but on the surface of the vomit I noticed a few small patches of brownish scum, which, on closer examination, appeared to consist of mucue stained with blood. I removed these, and, together with my friend Dr. Lionel Beale, examined them under the microscope; and we found, entangled in a fibrinous coagulum, numerous large nucleated cells precicely like cancer cells.

The more urgent symptoms yielded rapidly to appropriate treatment. I limited his food at once to animal jellies and fluids, such as could be completely or chiefly absorbed in the stomach, and forbade entirely the use of farinaceous food, which would have to pass out of the stomach before they could be digested. This obvious precaution was attended with immediate and entire relief of the vomiting. The rest of the treatment consisted in the use of creasote, lime-water, hydrocyanic acid; still, also, the hypodermic injections of morphia, to relieve the severe pain; but these were now alternated with doses of chloral and bromide of potassium combined, which quieted his nervous gystem and procured sleep. Thus we were able to diminish considerably the amount of morphia employed. He recovered rapidly from all the symptoms, except the gastrio pain, which I noticed again and again was rarely or never absent, except when it had been quieted by the bypodermic use of morphia. Under these cireumstances his friends objected to accept the very unfavourable prognosis I felt bound to give, and I was repeatedly urged to adopt the gall-stone theory as sufficient to account for all his symptoms. Three or four dark-looking, irregular concretions were produced which had formerly been passed, and which we were told were gall-stones. These were submitted to 
analysis, and ere reported to contain no cholesterin, and "to present more the character of urinary than biliary calculi." I had the adrantage of consultation with two very eminent physicians, and they both felt uncertain as to the precise nature of the case, and were both more disposed than I was to give weight to the evidence in favour of gallstones as the "fons et origo mali," as the patient was fond of expressing it. At any rate he rapidiy mended, and left London about the end of June for the north. About six weeks later I heard from him, to the effect that he was much better, that he had " turned the corner," and that he was abolut to start the following day for Sweden. His brother-in-law, however, wrote to me that "he thought him in a bad way when not under the influence of morphia."

The sequel of this case is told in the following report of his last fatal illness and the post-mortem examination by Dr. C. Forsenius, of Gothenburg:-

"Mr. — , sixty-two years old, arrived at Gothenburg, in Sweden, from the little bathing place Sârâ, on the $29 \mathrm{th}$ of August, 1874, in a comparatively good state of health. The sea-air and the voyage excited an unusual appetite, for which reason he took a rather copious breakfast, and ate also afterwards a good dinner. The same day, at 11 o'clock in the evening, he was suddenly affected with pain in the stomach and sickness. In the night he made a subcutaneous injection of morphia (81), and fell asleep. I was called at $4.30 \mathrm{~A}$.Mr., and found him then in a soporous state, with very dilated pupils, with a scarcely perceptible pulse of about 130 beats in the minute, with cold bluish hands and feet, with the belly very swelled, hard, and tympanitic. I then at once considered it to be a peritonitis from a perforating ulcer of the stomach, and ordered only to put a flannel moistened with oil and turpentine and a warm poultice on the beliy. At my next risit, between 10 and 11 o'clock in the forenoon, he was in agony, and died soon, very quietly. On the 31st August, 30 hours after death, I made a post-mortem examination in company with Dr. Ewart, and we found then all signs of death, the body exceedingly meagre, the belly very $s$ welled, the intestines covered with a viscid lymph, distended by gas, and in the upper part lively red; the ventricle, or stomach, very large and dilated, had a hole or perforation in the minor curvature, near the cardia, of round form and with rounded edges, of about the size of a sovereign, which had been covered by the underside of the liver, to which it had been lightly adherent; its mucous membrane was grayish and sloughy, with dark spots and strim of extravasated blood. The pylorus and the upper part of the duodenum were indurated and contracted, so that only the end of the little finger could be enforced in the passage, and the wall was there nearly half an inch thick. The liver was rather diminished in size, more dark and dense than usual. The gall-bladder was enlarged, as also the gall.duct (choledochus), but contained at present no gall-stone. The bead of the pancreas was also somewhat enlarged and indurated as the surrounding duodenum. The heart was of diminished size and contracted, empty from blood; its mitral valve was white and a little thickened; the aortic valves were ossificated, and the aorta was dilated to the double of its natural size (aneurisma) with many small atheromatous patches on its inner side. The lungs were otherwise healthy, but had in the agony been cedematous. There was also in the serous sacs of peritoneum, pleura, and pericardium, yellow, watery exudations. He had even very large hæmorrhoidal piles yet bleeding after the death."

I am much indebted to Dr. Forsenius for this careful and excellent account of the post-mortem examination.

The issue of this case possessed very great interest for all those who had seen the patient professionally during life, and were acquainted with his medical history, and it seems to me that there are many points of general interest to be noticed in it.

In the first place, it shows that scirrhous disease of the stomach may run a very protracted course, extending over a long series of years, and that the patient may enjoy long intervals of apparently perfect health. This latter fact was strongly dwelt upon by one of the physicians whom he consulted as a counter-indication of the existence of malignant disease. Here seveuteen rears elapsed between the first onset of gastric troubles and the fatal illness. In the second place, we learn the striking efficacy of judicious treatment in relieving the symptoms attending this disease.
The benefit derived from the Carlsbad course was remarkable, and lasted for some time. We can easily understand how a carefully restricted diet, and a daily washing out of the stomach and intestines with large quantities of warm, alkaline, aperient fluid should have the effect.

The hypodermic injection of morphia doubtless also contributed much to the patient's comparative comfort, although it at last lulled him into a false sense of security, masked important symptoms, and induced the most careful clinical observers (who had not the same advantages that I had of watching him from day to day) to hesitate to give an entirely unfavourable prognosis of the case.

The immediate cessation of the gastric irritation and vomiting on the change from farinaceous food to animal fluids and jellies which could be absorbed in the stomach, was a strong indication of the existence of obstructive disease at the pylorus, and it points to a fact that is of ten overlooked in practice-viz., that in some conditions of gastric or intestinal disorder, soft farinaceous foods are by no means easy of digestion.

Another point of interest in this case was the supposed existence of gall-stones as the original and sole cause of the symptoms. This opinion was put before us with so much circumstantial detail by the patient and his friends, and the success which had followed the treatment based on this opinion was pointed to as so evident; the actual passage of what were supposed to be biliary calculi; the long periods of freedom from suffering; the absence throughout the whole case of any local tumour or evident tenderness; all these facts naturally led us to give great weight to the considerations whether or not the symptoms could be thus satisfactorily accounted for. When, however, I observed the other obvious features of the case, at the time when I had the opportunity of seeing the patient daily, the constancy of the pain, except when under the intluence of morphia, coming on the instant the effect of the morphia passed off, the striking change in the symptoms produced by the change of diet, the persistent appearance of black stools, and, above all, the presence of bodies, having a perfect resemblance to cancer-cells, in some fragments of mucus on the surface of the vomit, - these facts assured me that although gall-stones might coexist, or might have existed, we had to do with a case of malignant disease of the pylorus running a somewhat unusual course.

Protracted as was the course of this case, there seems to be good reason for believing that had this patient realised fully the serious nature of his malady, and been willing to remain under medical supervision and direction; had he, in short, adopted the habits of an invalid, taken only such food as was ordered him, instead of travelling about as a sound man, and eating heartily of any food he felt disposed, his life might have been prolonged much longer. As it is, I think the case an important and instructive one, as illustrating a probably not inconsiderable class of cases in which malignant disease of the stomach exists for many years before coming to a fatal issue.

Hertford-street, $\mathrm{w}$.

\section{ILLUSTRATIONS OF ANTISEPTIC SURGERY.}

By HECTOR C. CAMERON, M.D.,

FITRA-MORAL LECTOREE ON SURGRBY, AXD SURGBON TO THE BOYAL INFIRMARY, GLASGOW.

\section{No. I.-CASES OF OPEN KNEE-JOINT.} (Concluded from $p .124$.

CASE 2. Compound comminuted fracture of the head of the tibia, communicating with the linee joint; free incision of the knee-joint; transverse fraciure of the patella; simple comminuted fracture of the femur; scalp wound; recovery.-J. Saged thirty-four, quarryman, was admitted into Ward 16 of the Royal Infirmary on April 20th, 1875, with numerons and severe injuries, caused by masses of stone being driven upon him while engaged in blasting at a quarry a few miles from Glasgow. The injuries were all upon the left side of the body. A little below the left knee-joint there was a ragged wound, an inch and a half in length, communicating with an extensively comminuted fracture of the head of the 